\title{
Adipocytes participate in storage in $\alpha$-galactosidase deficiency (Fabry disease)
}

\author{
Helena Hůlková • Milan Elleder
}

Received: 10 February 2010 /Revised: 18 June 2010 / Accepted: 22 June 2010/Published online: 14 July 2010

(C) The Author(s) 2010. This article is published with open access at Springerlink.com

\begin{abstract}
Ultrastructural and histochemical studies of bioptic and postmortem tissue samples from ten Fabry hemizygotes showed lysosomal storage in adipocytes as a constant feature of the classic phenotype of $\alpha$-galactosidase (GLA) deficiency. The storage was represented by a crescent-shaped line of storage lysosomes of varying thicknesses restricted to the perinuclear subplasmalemmal area. The ultrastructure of the storage lysosomes was dominated by concentric lipid membranes modified by simultaneous deposition of autofluorescent ceroid. Storage was widely expressed in adipose tissue. The number of storage lysosomes was increased, and the lysosomes were more clustered in adipocytes with less voluminous lipid content. The findings should attract interest to studies of adipose tissue biology in Fabry disease, a topic that has not been studied so far. In terms of cell biology, the observations represent indirect evidence of significant lysosomal turnover of $\alpha$ galactose lipid conjugates in adipocytes demasked by GLA deficiency. The results extend the thus far limited information on the adipocyte lysosomal system and its participation in lysosomal storage disorders.
\end{abstract}

Communicated by: Olaf Bodamer

Competing interest: None declared.

H. Hůlková $\cdot$ M. Elleder

Institute of Inherited Metabolic Disorders, Charles University,

1st Faculty of Medicine and Teaching Hospital,

Prague, Czech Republic

H. Hůlková

e-mail: hhulk@1f1.cuni.cz

\section{Elleder $(\square)$}

Institute of Inherited Metabolic Disorders,

Division B, Bldg.D, Ke Karlovu 2,

12808 Prague, Czech Republic

e-mail: melleder@cesnet.cz

\section{Introduction}

Fabry disease is an $\mathrm{X}$-linked deficiency of $\alpha$-galactosidase (GLA) resulting in widespread lysosomal storage of $\alpha$ galactose lipid conjugates represented mainly by, in decreasing order, globotriaosylceramide, digalactosyl ceramide (Desnick et al. 2001), and blood group B glycolipid (Ledvinova et al. 1997). The cell types expressing maximum storage are vascular endothelium, smooth muscle, cardiomyocytes, and podocytes. Storage, in varying degrees, has also been described in fibroblasts (Elleder 2010). There has only been one report that showed dermal adipocyte storage in a single case of Fabry disease (Le Charpentier et al. 1981). We present results of analysis of biopsies and postmortem samples in a series of ten Fabry patients that showed regular expression of storage in adipocytes.

\section{Material and methods}

Skin biopsies of seven male Fabry patients and samples from three autopsies of Fabry hemizygotes were examined. In all of them, diagnosis was verified biochemically (GLA deficiency) and/or at the DNA level (mutation in the GLA gene). Four patients were treated with enzyme replacement therapy (ERT) (see Table 1). The samples were processed by the standard procedures for ultrastructural examination, i.e., fixation in $4 \%$ paraformaldehyde, followed by osmification, dehydration, and embedding into a Epon-Araldite mixture. Thin sections were cut with a diamond knife, double-contrasted with uranyl acetate and lead citrate and examined using Tesla 500 and JEM 1200 EX electron microscopes. Autopsy samples were also embedded in paraffin and examined using autofluorescence in unstained 
sections or after staining with Sudan Black B and periodic acid-Schiff (PAS) for detection of ceroid-type lipopigment. Cryostat sections of unfixed tissues were examined in parallel using PAS in sections pre-extracted with anhydrous acetone [removal of triacylglycerols (TAGs)] and following total lipid extraction (chloroform-methanol 2:1 v/v, $1 \mathrm{~h}$, room temperature). In paraffin sections, the lysosomal storage compartment was demonstrated using an immunohistochemical detection of cathepsin D, as described elsewhere (Hulkova et al. 2009). Samples from autopsies of patients who died between the ages of 30 and 60 years without diagnosis of a lysosomal storage disorder were used as age-matched controls for detection of lipofuscintype lipopigment (age pigment). Nomenclature of the lipopigment type was used as recommended (Seehafer and Pearce 2006), i.e., ceroid as disease-induced lipopigment; lipofuscin as solely the age-related variant.

\section{Results}

The storage process in adipocytes was most easily discernible with the electron microscope. It was represented by a perinuclear crescent-shaped line of storage lysosomes of varying thicknesses that had been pushed into the subplasmalemmal area by the physiological cytoplasmic lipid storage depot. The storage lysosomes were represented by concentric lipid membranes, modified to varying degrees, by amorphous deposits of ceroid type lipopigment
(Fig. 1a). The number of storage lysosomes was increased, and the lysosomes were more clustered in adipocytes with less voluminous lipid content (Fig. 1b). With optical microscopy, storage was best observed in paraffin sections due to the prominent yellow autofluorescence or by positive staining with Sudan Black B and by the signal from the cathepsin D luminal lysosomal marker (Fig. 1c, d). In frozen sections, there was positive staining with PAS, abolished practically completely with total lipid preextraction. Only a slight residual staining of lipopigment persisted. Storage was seen in all regions examined (subcutaneous, subepicardial, retroperitoneal, perirenal). Often, there were fibroblast-like cells in the vicinity of adipocytes expressing a high degree lysosomal storage (preadipocytes?). Lipofuscin-type lipopigment in adipocytes of age-matched controls was either absent, or present in questionable amounts.

We found no correlation with the genotype of the patients. Adipocyte storage was seen already in the initial skin biopsies before any signs of organ failure. It correlated only with profound enzyme deficiency responsible for classic Fabry disease phenotype (Table 1). We had no possibility of examining organ-restricted phenotypes. Adipocyte lysosomal storage was not influenced by long-standing ERT, as could be inferred from the findings in all treated cases (see Table 1). This is in accord with our published observations on relative resistance of lysosomal storage to ERT in Fabry disease (Keslova-Veselikova et al. 2008).

Table 1 Survey of patients examined. All were of typical complex Fabry phenotype

\begin{tabular}{|c|c|c|c|c|c|c|}
\hline Patient & Biopsy (age) & Storage in adipocytes & $\begin{array}{l}\text { Enzyme activity } \\
\text { in leukocytes }{ }^{\mathrm{a}}\end{array}$ & Mutation & ERT & Further remarks \\
\hline 1. & $\begin{array}{l}\text { Skin biopsy (24) } \\
\text { Heart biopsy }\end{array}$ & $\begin{array}{l}+ \\
+\end{array}$ & 1.2 & p.Gln280Lys & Since age 45 & Alive \\
\hline 2. & Skin biopsy (25) & + & 1.4 & $\begin{array}{l}\text { p.Ser65ArgfsX61 } \\
\text { (p.Ser65fs) }\end{array}$ & Without & Died aged 50 on renal failure \\
\hline 3. & Skin biopsy (16) & + & 0.3 & p.Arg342Gln & Without & Alive \\
\hline 4. & Skin biopsy (33) & + & 0.9 & p.Arg342Gln & Without & Alive \\
\hline 5. & Skin biopsy (28) & + & 2.8 & p.Ala135Val & Without & Alive \\
\hline 6. & $\begin{array}{l}\text { Skin biopsy (33) } \\
\text { Heart biopsy }\end{array}$ & $\begin{array}{l}+ \\
+\end{array}$ & 2.4 & p.Leu268ValfsX4 & Since age 57 & Alive \\
\hline 7. & Heart biopsy & + & 0.4 & p.His225LeufsX5 & Since age 57 & Alive \\
\hline 8. & Not done & + in autopsy & Not done & p.Asp93Asn & Without & $\begin{array}{l}\text { Died aged } 47 \text {; brain embolisation } \\
\text { (heart thrombosis) }\end{array}$ \\
\hline 9. & Skin biopsy (37) & + in both biopsy and autopsy & Not done & p.Leu268ValfsX4 & Without & $\begin{array}{l}\text { Died aged } 44 \text {; brain embolisation } \\
\text { (heart thrombosis) }\end{array}$ \\
\hline 10 & Skin biopsy (41) & + in both biopsy and autopsy & 1 & p.Leu294Term & Since age 43 & Died after cardiosurgery aged 52 \\
\hline
\end{tabular}

Controls $n=100$, mean \pm standard deviation (SD) 53,8 $\pm 11,4$, range 32,2 -89

$E R T$ enzyme replacement therapy

${ }^{\mathrm{a}}$ Measured in peripheral leukocytes ( $\mathrm{nmol} / \mathrm{mg}^{-1} / \mathrm{h}^{-1}$ ) 

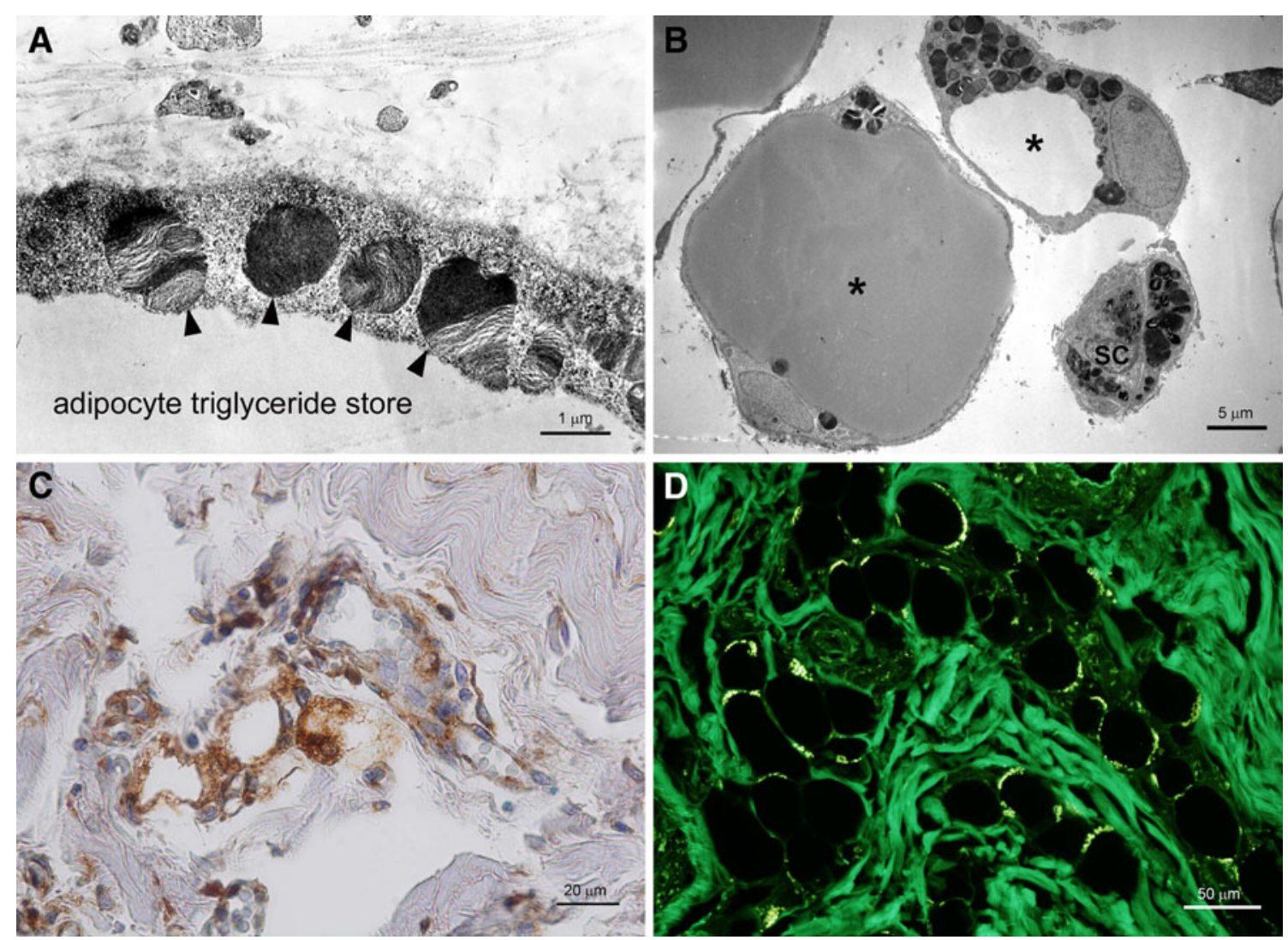

Fig. 1 a, b Skin biopsy of a male Fabry patient: a Detail of storage lysosomes in an adipocyte showing prevalence of lipid membranes. The storage lysosomal compartment is marked by arrowheads. b Two subcutaneous adipocytes (marked by asterisks) and a collapsed storing capillary $(S C)$ in their neighborhood. The number of storage lysosomes is inversely proportional to the amount of cytosolic lipid.

\section{Discussion}

In terms of molecular cell biology, the findings indicate the presence of limited, albeit significant, spontaneous lysosomal turnover of $\alpha$-galactose lipid conjugates demasked by GLA deficiency. Some findings (see above) suggest there might be an inverse relationship between TAG lipid depots and lysosomal storage. This brings to mind an observation in preadipocytes (Novikoff et al. 1980) that showed that the lysosomal system was active in autophagocytosis, which in Fabry disease could represent a source of lipid substrate. Similar activation of the lysosomal system was described in the process of mouse L-cell adipocyte differentiation (Borisov 1982). A similar relationship between physiological lipid storage deposits and the degree of lysosomal expansion in lysosomal storage disorders was described in Ito cells (Elleder 1984; Elleder 2010). Knowledge about adipocyte participation in other lysosomal storage disorders is restricted to neuronal ceroid lipofuscinosis type 2 (Rowan and Lake 1995) and c, d Paraffin sections of autopsy specimens of subepicardial adipose tissue: c Strong subplasmalemmal signal for cathepsin D in adipocyte lysosomes (controls are negative; not shown). d Strong autofluorescence of subplasmalemmal lysosomes in adipocytes, indicating significant participation of ceroid in the storage

Elleder M (unpublished observations). Our results extend the knowledge of the adipocyte lysosomal system that was directly shown to be active under experimental conditions (Borisov 1982; Meshkinpour et al. 1996). Indirect evidence of its presence stems from several experimental studies (Hou et al. 2009; Kobayashi et al. 1980; Kovsan et al. 2007; Lee and Fried 2006; Palacios et al. 2001; Zvonic et al. 2005). What is really missing is evidence for possible TAG lysosomal turnover in adipocytes. Our unpublished results, limited to several skin biopsies of cholesteryl ester storage disease (CESD), showed no presence of lysosomal storage (unpublished observations). We are not aware of any analogous studies in human cases of Wolman disease. Our observation involving a single case (unpublished) revealed no discernible lysosomal storage in adipocytes (unpublished). This contrasts with the striking impact of acid lipase deficiency on adipose tissue in the mouse model, featured by progressive loss of white adipose tissue and monovacuolar transformation of brown adipose tissue (Du et al. 2001). 


\section{Conclusion}

Our report extends the list of cells affected by lysosomal storage in GLA deficiency, which may encourage evaluation of adipose tissue function in patients with Fabry disease. From a more general point of view, it raises the question of whether the storage-compromised lysosomal system interferes with regulation of adipocyte differentiation, fat mobilization, and endocrine function of adipose tissue. There are experiments that support this view (Smith and Jarett 1982).

Acknowledgement The study was supported by the Ministry of Education of the Czech Republic (project No. MSM 0021620806). We thank Drs. Josef Houštěk and Michal Haluzík for valuable conceptual remarks.

Open Access This article is distributed under the terms of the Creative Commons Attribution Noncommercial License which permits any noncommercial use, distribution, and reproduction in any medium, provided the original author(s) and source are credited.

\section{References}

Borisov AB (1982) Changes in lysosomal enzyme activity in the process of L-cell adipocyte differentiation. Tsitologiia 24:1440-1443

Desnick RJ, Ioannou YA, Eng CM (2001) Alpha-galactosidase A deficiency: Fabry disease. In: Scriver CR, Beaudet AL, Sly WS, Valle D (eds) The metabolic and molecular bases of inherited disease. McGraw-Hill, New York, pp 3733-3774

Du H, Heur M, Duanmu M et al (2001) Lysosomal acid lipase-deficient mice: depletion of white and brown fat, severe hepatosplenomegaly, and shortened life span. J Lipid Res 42:489-500

Elleder M (1984) Ito cells in lysosomal storage disorders. An ultrastructural study. Virchows Arch B pathol 46:13-19

Elleder M (2010) Subcellular, cellular and organ pathology of Fabry Disease. In: Elstein D, ed. Fabry's Disease. Springer (in press)

Hou JC, Williams D, Vicogne J, Pessin JE (2009) The glucose transporter 2 undergoes plasma membrane endocytosis and lysosomal degradation in a secretagogue-dependent manner. Endocrinology 150:4056-4064
Hulkova H, Ledvinova J, Poupetova H, Kohout A, Malinova V, Elleder M (2009) Autopsy case of Gaucher disease type I in a patient on enzyme replacement therapy. Comments on the dynamics of persistent storage process. J Inherit Metab Dis 32:551-559

Keslova-Veselikova J, Hulkova H, Dobrovolny R et al (2008) Replacement of alpha-galactosidase A in Fabry disease: effect on fibroblast cultures compared with biopsied tissues of treated patients. Virchows Arch 452:651-665

Kobayashi M, Iwasaki M, Shigeta Y (1980) Receptor mediated insulin degradation decreased by chloroquine in isolated rat adipocytes. $\mathrm{J}$ Biochem 88:39-44

Kovsan J, Ben-Romano R, Souza SC, Greenberg AS, Rudich A (2007) Regulation of adipocyte lipolysis by degradation of the perilipin protein: nelfinavir enhances lysosome-mediated perilipin proteolysis. J Biol Chem 282:21704-21711

Le Charpentier Y, Crouzet J, Le Charpentier M et al (1981) Fabry's disease without cutaneous angiokeratoma: diagnosis by electron microscope study of skin biopsy (author's transl). Sem Hôp 57:78-82

Ledvinova J, Poupetova H, Hanackova A, Pisacka M, Elleder M (1997) Blood group B glycosphingolipids in alpha-galactosidase deficiency (Fabry disease): influence of secretor status. Biochim Biophys Acta 1345:180-187

Lee MJ, Fried SK (2006) Multilevel regulation of leptin storage, turnover, and secretion by feeding and insulin in rat adipose tissue. J Lipid Res 47:1984-1993

Meshkinpour H, Vaziri ND, Zhou XJ et al (1996) Effects of experimental hemosiderosis on intestinal morphology, permeability, and tissue iron content. Dig Dis Sci 41:984-988

Novikoff AB, Novikoff PM, Rosen OM, Rubin CS (1980) Organelle relationships in cultured 3T3-L1 preadipocytes. J Cell Biol 87:180-196

Palacios S, Lalioti V, Martinez-Arca S, Chattopadhyay S, Sandoval IV (2001) Recycling of the insulin-sensitive glucose transporter GLUT4. Access of surface internalized GLUT4 molecules to the perinuclear storage compartment is mediated by the Phe5-Gln6Gln7-Ile8 motif. J Biol Chem 276:3371-3383

Rowan SA, Lake BD (1995) Tissue and cellular distribution of subunit c of ATP synthase in Batten disease (neuronal ceroid-lipofuscinosis). Am J Med Genet 57:172-176

Seehafer SS, Pearce DA (2006) You say lipofuscin, we say ceroid: defining autofluorescent storage material. Neurobiol Aging 27:576-588

Smith RM, Jarett L (1982) Ultrastructural basis for chloroquineinduced increase in intracellular insulin in adipocytes: alteration of lysosomal function. Proc Natl Acad Sci USA 79:7302-7306

Zvonic S, Baugh JE Jr, Arbour-Reily P, Mynatt RL, Stephens JM (2005) Cross-talk among gp130 cytokines in adipocytes. J Biol Chem 280:33856-33863 